\title{
Congenital hypertrophy of the retinal pigment epithelium and APC mutations in two Chinese families with familial adenomatous polyposis
}

C.P. Pang

J.W.Y. Keung

D.S.P. Fan

D.S.C. Lam

Department of

Ophthalmology \& Visual Sciences

Chinese University of Hong Kong

Shatin, Hong Kong

\section{N.L.S. Tang}

Department of Chemical Pathology

Chinese University of

Hong Kong

Shatin, Hong Kong

J.W.Y. Lau

Department of Surgery

Chinese University of

Hong Kong

Shatin, Hong Kong

Dr C.P. Pang

Department of

Ophthalmology \& Visual

Sciences

The Chinese University of

Hong Kong

3/F, Hong Kong Eye Hospital

147K Argyle Street Kowloon Hong Kong

Tel: +852 27623129

Fax: +852 27159490

e-mail: cppang@cuhk.edu.hk

Proprietary interests: None

Supported in part by: (1) a direct grant of the Medical Panel, the Chinese

University of Hong Kong, (2) Mrs Annie Wong Eye

Foundation, Hong Kong, and (3) Mr W.K. Lee Eye Foundation, Hong Kong

Presented in part at the annual ARVO meeting, May 1997, Florida, USA

Received: 3 February 1999

\section{Abstract}

Purpose Congenital hypertrophy of the retinal pigment epithelium (CHRPE) exists almost exclusively among familial adenomatous polyposis (FAP) patients with adenomatous polyposis coli (APC) mutations between codon 413 in exon 9 and codon 1387 in exon 15. We investigated the locality of APC mutations in relationship to the occurrence of CHRPE in two Chinese families with FAP.

Methods Genomic DNA of available members of two unrelated Chinese FAP families was investigated for sequence alteration in the APC gene by polymerase chain reaction and direct sequencing. All subjects were examined by binocular indirect ophthalmoscopy (BIO) for CHRPE.

Results A mutation in exon 6, Arg216Stop, was identified in one patient with FAP and CHRPE. An Arg283Stop mutation in exon 8 was found in 5 members in another family; 4 of them had FAP and all had small hypopigmented white lesions, probably a new type of CHRPE.

Conclusions We found two mutations, Arg216Stop and Arg283Stop, upstream of codon 413 in FAP patients presenting with CHRPE. Arg283Stop has not previously been reported in such patients. A large-scale study on CHRPE and APC mutations in Chinese FAP patients is required to affirm their interrelationships and the significance of the hypopigmented white lesions.

\section{Key words APC mutations, Chinese FAP, CHRPE}

Familial adenomatous polyposis (FAP) is an autosomal dominant disease characterised by hundreds and thousands of adenomatous polyps in the colon. ${ }^{1}$ The affected individual typically develops multiple polyps in the colon during the second or third decade of life. These
C.P. PANG,

JOYCE W.Y. KEUNG,

NELSON L.S. TANG,

DOROTHY S.P. FAN,

JOSEPH W.Y. LAU,

DENNIS S.C. LAM adenomas are pre-malignant lesions that will inevitably progress to carcinoma unless the affected colon is removed. ${ }^{2}$ FAP is pan-ethnic, prevalence ranging from 1 in 8000 to 1 in 15000 live births in different populations. ${ }^{1,3,4}$

Most FAP patients have extracolonic complications, including congenital hypertrophy of the retinal pigment epithelium (CHRPE), desmoid tumours, osteomas and epidermoid cysts. ${ }^{5} \mathrm{CHRPE}$ is the most common extracolonic feature of FAP and is usually identifiable early after birth. It is regarded as a sensitive and useful marker for identification of pre-symptomatic carriers in FAP families. ${ }^{6,7}$ CHRPE lesions are classified morphologically into types A, B, C and D. ${ }^{8}$ Type A, which are oval pigmented lesions with a pale halo, are the most frequent among FAP patients. ${ }^{9}$ In another grading system based on size and number of lesions in both eyes, a patient is considered CHRPE positive when a CHRPE score is greater than $3 .^{10}$ The typical change of the retinal pigment epithelium in CHRPE is hyperpigmentation. However, hypopigmentation could also be present, such as the pale halo surrounding the pigmented CHRPE in the classic type A lesion (see Fig. 2) We have reported the occurrence of type $\mathrm{E}$ CHRPE in Chinese FAP patients and their relatives. ${ }^{11}$ This type of CHRPE lesion is hypopigmented, white and small (see Fig. 2).

The adenomatous polyposis coli (APC) gene on chromosome $5 q 21-22$ is responsible for FAP. ${ }^{12,13}$ It consists of 15 exons and 14 introns spanning more than 100 kilobases. The known coding sequences contain 8972 nucleotides encoding for a polypeptide of 2843 amino acids. More than 700 mutations in the APC gene have been reported in FAP patients. ${ }^{14-17}$ The majority of sequence aberrations are frameshift or nonsense mutations that lead to a truncated protein. The most common mutations are codon 302 in exon 8 , codon 625 in exon 14 and codons 
1061, 1309 and 1546 in exon 15. There is strong correlation between the locality of APC mutations and phenotypic features. In FAP patients with profuse adenomatous polyps (more than 5000 in number), APC mutations are mostly found between codons 1255 and 1467 in exon $15 .{ }^{18}$ CHRPE exists almost exclusively among patients with APC mutations between codon 413 in exon 9 and codon 1387 in the $5^{\prime}$ region of exon 15. ${ }^{14,18,19}$ Mutations in the 5 ' end of APC, such as exons 1 , 2 and 3 , are rare and usually cause the attenuated type of FAP with far fewer polyps. They may lead to late-onset colorectal cancer. ${ }^{20}$ Here we report two Chinese FAP families in which all the 5 affected patients who carry APC mutations upstream to exon 9 are CHRPE positive.

\section{Methods}

\section{Patients}

In the Eye Clinic, Prince of Wales Hospital, 2 Chinese patients with histologically proven FAP were found to have CHRPE in both eyes. They and their family members were recruited into this study, which was approved by the Ethics Committee for Human Research, the Chinese University of Hong Kong. Informed consent has been obtained from all study subjects. The study protocol has adhered to the principles enunciated in the present Declaration of Helsinki.

\section{Ophthalmological and endoscopic examination}

All study subjects received pupillary dilation and fundal examination on two separate occasions with binocular indirect ophthalmoscopy (BIO). The number and type were noted by drawing on retinal maps. The presence of adenomatous polyps in the study subjects was investigated independently by our surgical colleague with endoscopy.

\section{Polymerase chain reaction}

Genomic DNA extracted from peripheral blood was used as template for polymerase chain reaction (PCR) amplification of the coding exons of the APC gene using 22 primer pairs as described. ${ }^{12,21,22}$ Each PCR mixture contained $3.6 \mathrm{ng}$ genomic DNA, $0.2 \mathrm{mM}$ of each deoxynucleotide (dNTP), 0.5 U Taq DNA polymerase (GIBCO BRL, Gaithenberg, MD), $0.3 \mu \mathrm{g}$ of each primer, 1.5-2.0 mM magnesium chloride in a final volume of $25 \mu$ l. PCR was carried out in a thermal cycler (MJ Research): initial denaturation at $94{ }^{\circ} \mathrm{C}$ for $5 \mathrm{~min}$, followed by 35 cycles of denaturation at $94^{\circ} \mathrm{C}$ for $30 \mathrm{~s}$, annealing at $54-64{ }^{\circ} \mathrm{C}$ for $1 \mathrm{~min}$ and elongation at $72{ }^{\circ} \mathrm{C}$ for $3 \mathrm{~min}$.

\section{Direct DNA sequencing}

The PCR-amplified DNA samples were purified with the use of a Microspin S-300 HR column (Pharmacia Biotech, Sweden). The primers as for PCR were used in the sequencing reactions and were labelled at the 5 '-end with $\gamma^{32} \mathrm{P}$-dATP (Amersham, Buckingham, UK). The reaction mixture contained $0.2 \mu \mathrm{g}$ primer, $1 \mu \mathrm{l}$ of $\gamma^{32} \mathrm{P}-\mathrm{dATP}$ and $1 \mathrm{U} \mathrm{T} 4$ polynucleotide kinase in a final volume of $10 \mu \mathrm{l}$. The mixture was incubated at $37^{\circ} \mathrm{C}$ for $30 \mathrm{~min}$, and then heated at $95^{\circ} \mathrm{C}$ for $5 \mathrm{~min}$ to inactivate the kinase. Four microlitres of a master sequencing mix, which contained $2 \mu \mathrm{l}$ of the reaction mixture, $1 \mu \mathrm{l}^{32} \mathrm{P}$-labelled primer, $2 \mu \mathrm{l}$ Thermo sequenase DNA polymerase (Amersham), $20 \mathrm{ng}$ purified DNA template and $9.5 \mu \mathrm{l}$ water, was added to four tubes containing $4 \mu \mathrm{l}$ each of the ddATP, ddCTP, ddGTP and ddTTP termination mix. After a cycling process using the same temperature programme as for PCR, the sequencing reaction products were analysed by denaturing $6 \%$ polyacrylamide gel (acrylamide:bisacrylamide 19:1) electrophoresis and detected by autoradiography.

\section{Results}

An APC mutation located proximal to exon 9 was detected in each family: an Arg $\rightarrow$ Stop mutation in codon 216 due to a $\mathrm{C} \rightarrow \mathrm{T}$ substitution at nucleotide 646 in exon 6 (Fig. 1a), and an Arg $\rightarrow$ Stop mutation in codon 283 due to a $\mathrm{C} \rightarrow \mathrm{T}$ substitution at nucleotide 847 in exon 8 (Fig. 1b). Members of family A only had types A and B CHRPE lesions while family B had types B and E (Fig. 2). There was a dominance of type E CHRPE lesions in

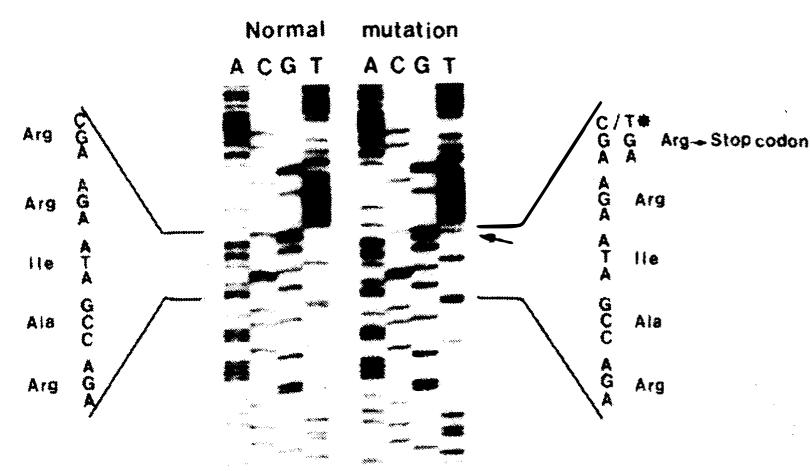

(a)

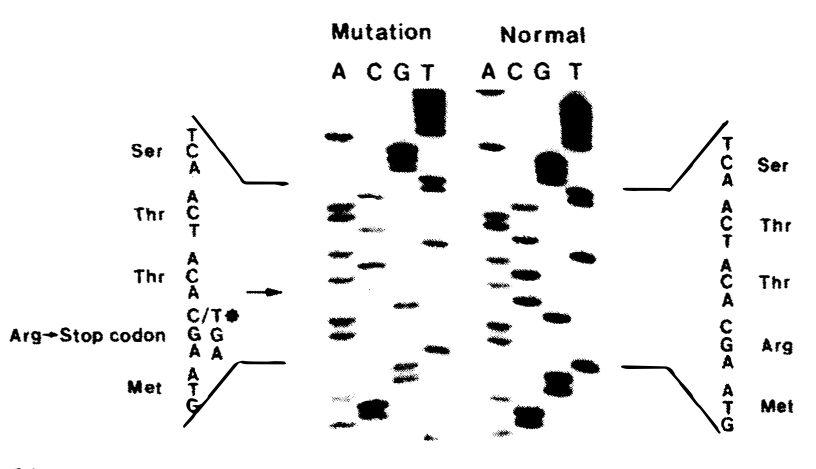

(b)

Fig. 1. Sequence analysis of the amplified exons of the APC gene. (a) Heterozygosity for CGA $\rightarrow T G A$ in exon 6 was detected at codon 216 leading to a stop codon in FAP patient AII-1. (b) Heterozygosity for CGA $\rightarrow$ TGA in exon 8 was detected at codon 283 leading to a stop colon in FAP patient BII-1. 


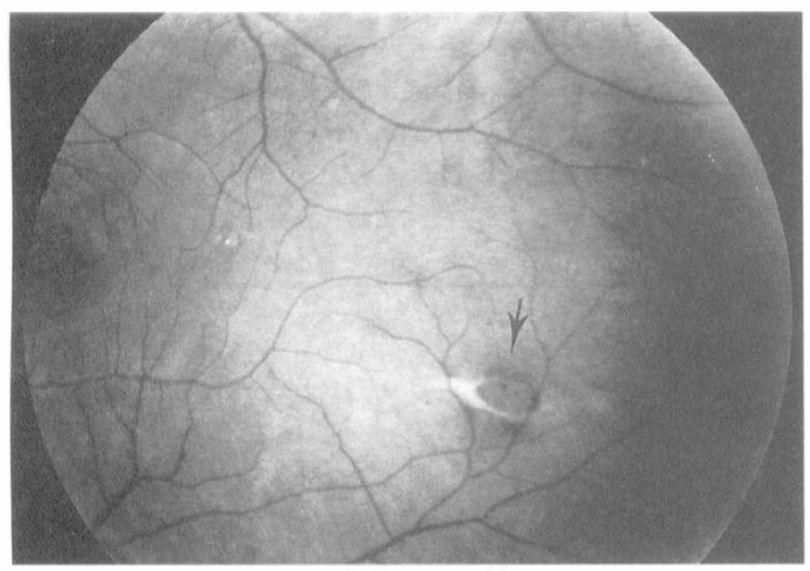

(a)

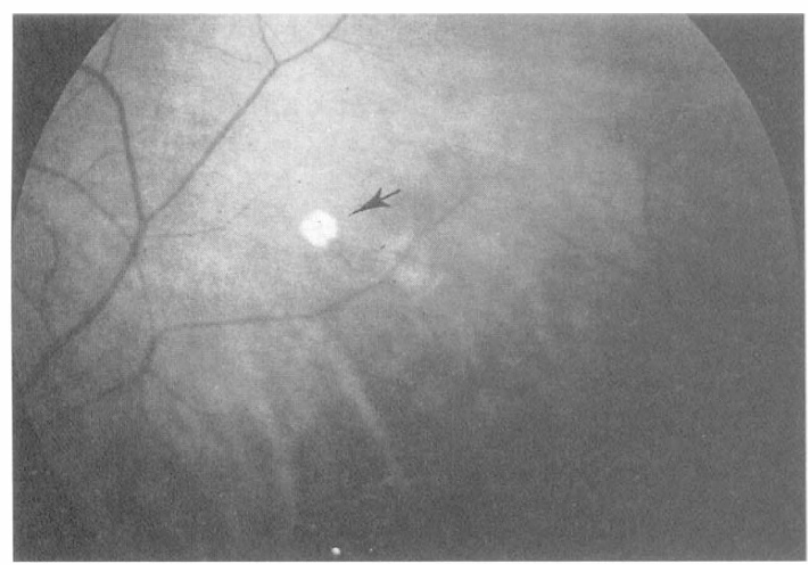

(b)

Fig. 2. Congenital hypertrophy of the retinal pigment epithelium (CHRPE) found in this study. (a) Typical type A lesions. (b) Typical hypopigmented, white and small type E lesions.

family B, 22 of 30 (73\%) CHRPE lesions being of this type (Table 1). This type of lesion was hypopigmented, white and small.

CHRPE was the only extracolonic complication in the FAP patients of these two families. Desmoid tumours, osteomas and epidermoid cysts were not present. In family A, FAP patient AII-1 had CHRPE in both eyes. Her daughter AIII-2 had two CHRPE lesions but she was not an APC mutation carrier (Fig. 3). Among the 5 Arg283Stop carriers in family B only BIII-2 did not have
FAP. FAP patients BII-1, BII-5 and BII-7 all carried Arg283Stop but they mainly had the new type E lesions. Sisters BII-9 and BII-10 did not carry any APC mutation and were not affected by FAP but they had type E CHRPE in both eyes. Subject BI-2 died of FAP several years before our study (Fig. 4).

\section{Discussion}

The APC protein forms complexes with catenins, which interact with E-cadherin. ${ }^{23}$ E-cadherin has an important role in cell-cell and cell-extracellular matrix communication through the adherin junctions.

Deleterious mutations of the APC gene lead to disrupted cell-cell interaction and poorly regulated cell growth. A recent developmental study in mice has shown that the APC gene is critical in the regulation of retinal pigment epithelium (RPE) proliferation. ${ }^{24}$ The mutated protein produced by a stop codon in the APC sequence 3' of exon 9 may interefere with the proliferative control of RPE and results in CHRPE. ${ }^{23}$ CHRPE is known to occur in FAP patients with APC mutations between codons 413 and 1387. ${ }^{14,18}$ Patients with mutations outside this region are negative for CHRPE. The only known exception is a patient carrying the Arg216Stop mutation in exon 6. He had both FAP and CHRPE. ${ }^{25}$

In this study we found two mutations proximal to codon 413 in FAP patients presenting with CHRPE. Arg283Stop has not previously been reported in FAP patients with CHRPE. ${ }^{14}$ Arg216Stop and Arg283Stop add examples of the occurrence of CHRPE in FAP patients carrying APC mutations in positions $5^{\prime}$ to codon 413. ${ }^{14,18,19}$ The locality of the APC mutation affects the clinical manifestations. More FAP-CHRPE patients have APC mutations between codons 413 and 1387 than other regions. ${ }^{14-17}$ APC mutations in attenuated adenomatous polyposis coli (AAPC), which is a less severe form of FAP, mostly cluster in the 5 region. ${ }^{20}$ These patients have fewer colonic polyps and fewer extracolonic complications, such as CHRPE, than those with classic FAP. ${ }^{26,27}$

Table 1. Clinical features and APC mutations in the two FAP families

\begin{tabular}{|c|c|c|c|c|c|c|c|c|c|c|c|c|c|c|}
\hline \multirow[b]{3}{*}{ Subject } & \multirow[b]{3}{*}{ FAP } & \multicolumn{12}{|c|}{ CHRPE } & \multirow[b]{3}{*}{ APC mutation } \\
\hline & & \multirow{2}{*}{$\begin{array}{l}\text { No. of } \\
\text { lesions }\end{array}$} & \multicolumn{5}{|c|}{ Type } & \multicolumn{3}{|c|}{ Size } & \multicolumn{3}{|c|}{ Localisation } & \\
\hline & & & A & $\mathrm{B}$ & C & $\mathrm{D}$ & $E$ & $<0.5 \mathrm{DD}$ & $0.5-1.0 \mathrm{DD}$ & $>1.0 \mathrm{DD}$ & $\mathrm{PP}$ & $\mathrm{Eq}$ & Peri & \\
\hline AII-1 & + & 5 & 3 & 2 & 0 & 0 & 0 & 1 & 2 & 2 & 0 & 0 & 5 & Arg216Stop \\
\hline AIII-2 & - & 2 & 2 & 0 & 0 & 0 & 0 & 2 & 0 & 0 & 1 & 1 & 0 & - \\
\hline BII-1 & + & 7 & 0 & 1 & 0 & 0 & 6 & 7 & 0 & 0 & 1 & 4 & 2 & Arg283Stop \\
\hline BII-5 & + & 2 & 0 & 0 & 0 & 0 & 2 & 2 & 0 & 0 & 1 & 1 & 0 & Arg283Stop \\
\hline BII-7 & + & 7 & 0 & 1 & 0 & 0 & 6 & 6 & 1 & 0 & 2 & 3 & 2 & Arg283Stop \\
\hline BII-9 & - & 5 & 0 & 0 & 0 & 0 & 5 & 5 & 0 & 0 & 0 & 2 & 3 & - \\
\hline BII-10 & - & 2 & 0 & 2 & 0 & 0 & 0 & 2 & 0 & 0 & 1 & 0 & 1 & - \\
\hline BIII-1 & + & 5 & 0 & 4 & 0 & 0 & 1 & 5 & 0 & 0 & 2 & 2 & 1 & Arg283Stop \\
\hline BIII-2 & - & 2 & 0 & 0 & 0 & 0 & 2 & 2 & 0 & 0 & 0 & 1 & 1 & Arg283Stop \\
\hline
\end{tabular}

All members of family B carry the $1458 \mathrm{C} \rightarrow \mathrm{T}$ polymorphism in exon 11 . Family members without any clinical features or APC sequence variations were not listed.

$\mathrm{DD}$, disc diameter (mm); PP, posterior pole; Eq, equator; Peri, peripheral. 


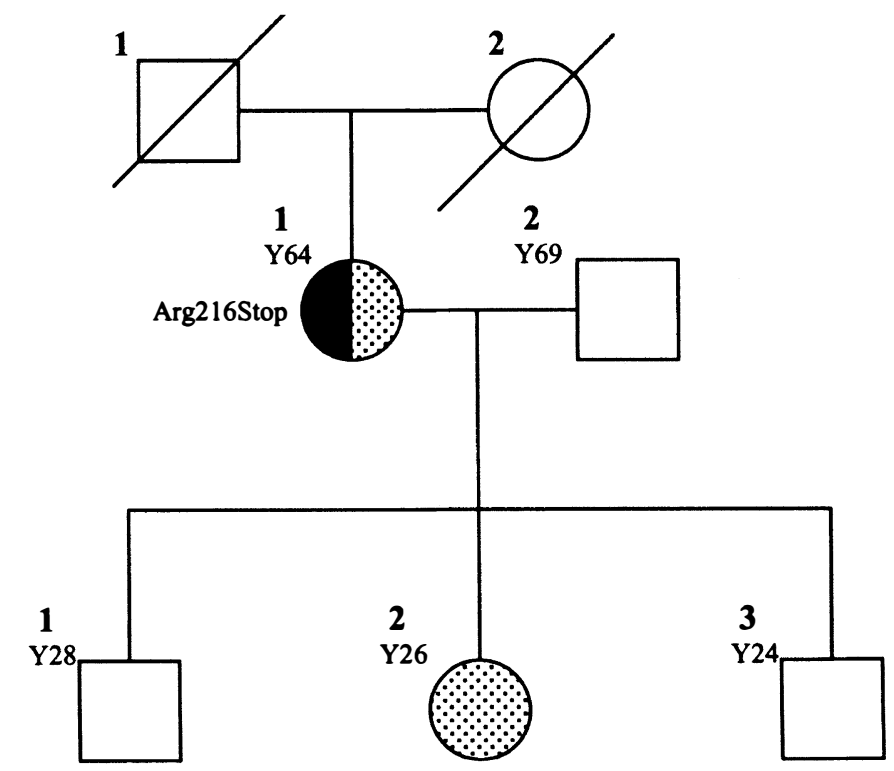

Fig. 3. Pedigree of family A. Black symbol indicates an affected patient with FAP, stippling indicates CHRPE and blank symbols indicate unaffected or unknown status at the time of study. $Y$ is the age of the subject (in years) when recruited.

CHRPE is well recognised as an early clinical marker with good predictive value for FAP..$^{19,28,29}$ The sensitivity of CHRPE for detection of APC mutation was up to $75 \%$ and specificity almost $100 \%$. However, detection of CHRPE may not be unequivocal. It is affected by definition. Subject BII- 5 in this study had FAP and the Arg283Stop mutation (Table 1). He only had two small type E CHRPE lesions and would not be classified as CHRPE-positive on the basis of conventional criteria. ${ }^{8,10}$ Subject BIII-2 of the same family also carried the Arg283Stop mutation and two small type E CHRPE lesions. She was only 20 years old at the time of study and had a high risk of developing FAP. In this family, among the four APC mutation carriers who had FAP, subjects BII-1, BII-5 and BII-7 would not be classified as CHRPE-positive according to the conventional system ${ }^{8,10}$ (Table 1). Only subject BIII-1, who had four type B lesions, would be designated CHRPE positive (Fig. 4). Such findings cast doubt on the reliability of CHRPE as a pre-symptomatic test for FAP. While change in the RPE in CHRPE is mainly hyperpigmentation, there is also hypopigmentation, such as the pale halo surrounding the pigmented CHRPE in type A lesions (Fig. 2). The hypopigmented, white and small lesions designated as type E may be a new type of CHRPE. ${ }^{11}$ Type E has not been reported in other populations although it was the predominant form of RPE lesions in family B of this study on Chinese (Table 1).

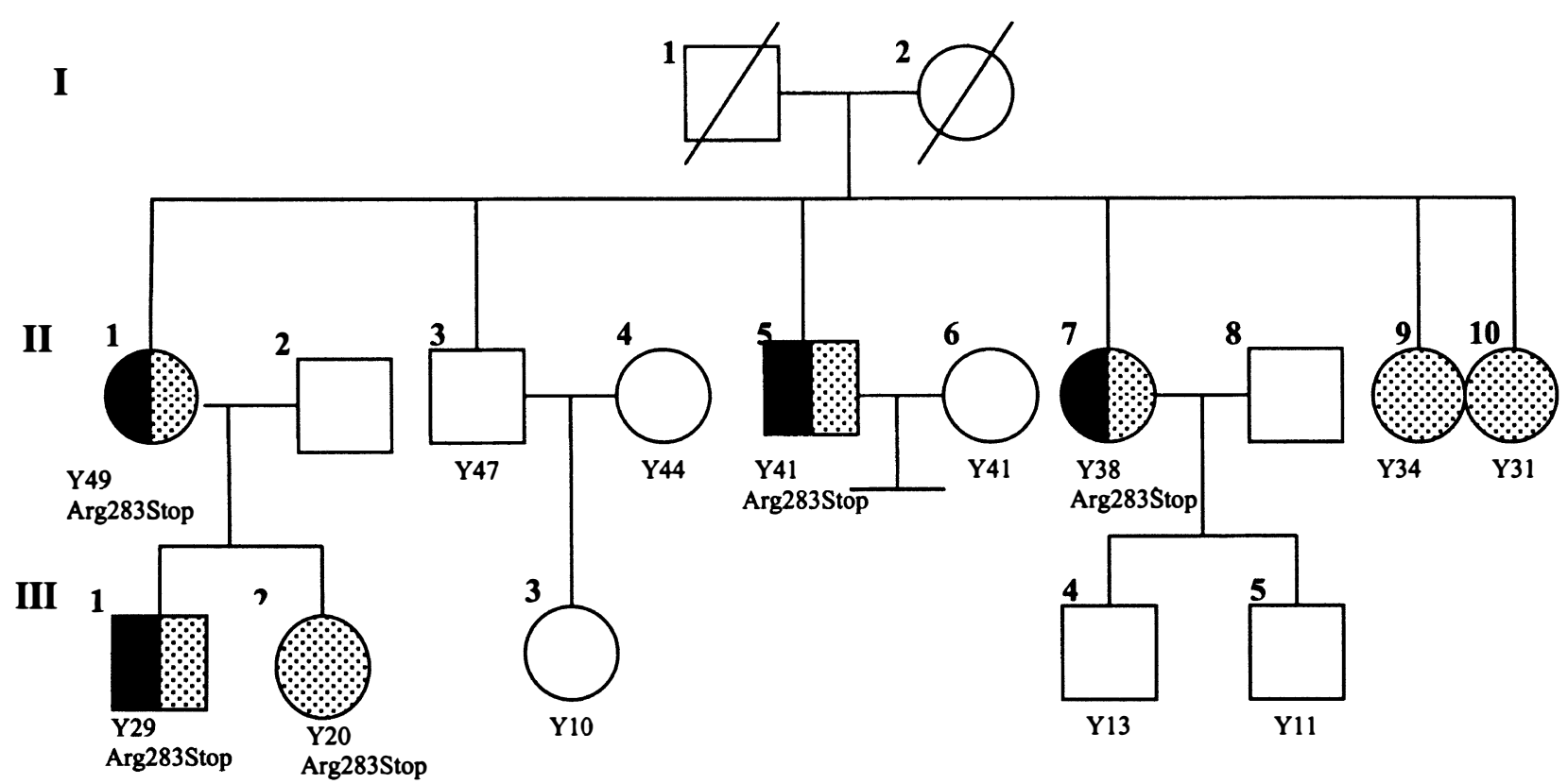

Fig. 4. Pedigree of Family B. Black symbol indicates an affected patient with FAP, stippling indicates CHRPE and blank symbols indicate unaffected or unknown status at the time of study. $Y$ is the age of the subject (in years) when recruited. 
Meanwhile, CHRPE was found in 3 of our study subjects without an APC mutation (Table 1). They did not have FAP. Two carriers of the Arg283Stop mutation, BII-5 and BIII-2, had only two small type E CHRPE lesions. Such a mild phenotype may not be sufficient to classify them as CHRPE-positive. There was therefore a lack of correlation between the occurrence of CHRPE and APC mutations.

Our results also suggest APC mutations may not be the only cause of CHRPE. However, it is also possible that upstream mutations in the 5' region of the gene may result in truncated but short APC proteins which are unstable and can be rapidly denatured. Therefore, these mutant proteins may be present in small amounts and lead to milder deleterious effects in cell regulation, which do not result in CHRPE.

The large variation in pigment epithelial changes in FAP, even within families, is well recognised. ${ }^{9,30}$ Our results suggest that such variation may be race-specific. While there is a lack of correlation between CHRPE and APC mutations, Chinese patients with CHRPE are probably more likely to have FAP and may be more likely to have mutations in the $5^{\prime}$ half of the APC gene. The picture, however, is not clear. A large-scale study on CHRPE and APC mutations in Chinese FAP families is required to confirm their inter-relationships and to ascertain whether the type $\mathrm{E}$ form of $\mathrm{CHRPE}$ is a genuine phenomenon.

\section{References}

1. Utsunomiya J, Miki Y, Kuroki T, Iwama T. Phenotypic expressions of Japanese patients with familial adenomatous polyposis. In: Herrera L, editor. Familial adenomatous polyposis. New York: Alan R Liss, 1990:101-7.

2. Murday V, Slack J. Inherited disorders associated with colorectal cancer. Cancer Surv 1989;8:139-57.

3. Bulow SHN, Hauge M. The incidence and prevalence of familial polyposis coli in Denmark. Scand J Soc Med 1986;14:67-74.

4. Jarvinen HJ. Epidemiology of familial adenomatous polyposis in Finland: impact of family screening on the colorectal cancer rate and survival. Gut 1992;33:357-60.

5. Kinzler KW, Nilbert MC, Su L, et al. Identification of FAP locus genes from chromosome 5q21. Science 1991;253:661-5.

6. Diaz-Llopis M, Menezo JL. Congenital hypertrophy of retinal pigment epithelium in familial adenomatous polyposis. Arch Ophthalmol 1988;106:412-3.

7. Lyons LA, Lewis RA, Strong LC, et al. A genetic study of Gardner syndrome and congenital hypertrophy of the retinal pigment epithelium. Am J Hum Genet 1988;42:290-6.

8. Berk T, Cohen Z, McLeod RS, Parker JA. Congenital hypertrophy of the retinal pigment epithelium as a marker for familial adenomatous polyposis. Dis Colon Rectum 1988;31:253-7.

9. Polkinghorne PJ, Ritchie S, Neale K, et al. Pigmented lesions of the retinal pigment epithelium and familial adenomatous polyposis. Eye 1990;4:216-22.

10. Valanzano R, Cama A, Volpe R, et al. Congenital hypertrophy of the retinal pigment epithelium in familial adenomatous polyposis. Cancer 1996;78:2400-10.

11. Lam DSC, Kwok SPY, Kwok AKH, et al. Incidence and predictive value of congenital hypertrophy of retinal pigment epithelium (CHRPE) in Chinese familial adenomatous polyposis patients. Chin Med J 1998;111:278-81.
12. Groden J, Thliveris A, Samowitz W, et al. Identification and characterisation of the familial adenomatous polyposis coli gene. Cell 1991;66:589-600.

13. Nishisho I, Nakamura Y, Miyoshi Y, et al. Mutations of chromosome $5 q 21$ genes in FAP and colorectal cancer patients. Science 1991;253:665-9.

14. Olschwang S, Tiret A, Laurent-Puig P, et al. Restriction of ocular fundus lesions to a specific subgroup of APC mutations in adenomatous polyposis coli patients. Cell 1993;75:959-68.

15. Beroud C, Soussi T. APC gene: database of germline and somatic mutations in human tumors and cell lines. Nucleic Acids Res 1996;24:121-4.

16. Gismondi V, Bafico A, Biticchi R, et al. Characterisation of 19 novel and six recurring APC mutations in Italian adenomatous polyposis patients, using two different mutation detection techniques. Hum Mutat 1997;9:370-3.

17. Armstrong J, Davies DR, Guy S, et al. APC mutations in familial adenomatous polyposis families in Northwest England. Hum Mutat 1997;10:376-80.

18. Caspari R, Oslchwang S, Friedl W, et al. Familial adenomatous polyposis: desmoid tumours and lack of ophthalmic lesions (CHRPE) associated with APC mutations beyond codon 1444. Hum Mol Genet 1995;4:337-40.

19. Reck AC, Bunyan D, Eccles D, Humphry R. The presence of congenital hypertrophy of the retinal pigment epithelium in a subgroup of patients with adenomatous polyposis coli mutations. Eye 1997;11:298-300.

20. Spirio L, Olschwang S, Groden J, et al. Alleles of the APC gene: an attenuated form of familial polyposis. Cell 1993;75:951-7.

21. Miyoshi $Y$, Ando H, Nagase $H$, et al. Germ-line mutations of APC gene in 53 familial adenomatous polyposis patients. Proc Natl Acad Sci USA 1992;89:4452-6.

22. Yashima K, Nakamori S, Murakami Y, et al. Mutations of the adenomatous polyposis coli gene in the mutation cluster region: comparison of human pancreatic and colorectal cancers. Int J Cancer 1994;59:43-7.

23. Rubinfeld B, Souza B, Albert I, et al. The APC protein and E-cadherin form similar but independent complexes with alpha-catenin, beta-catenin, and plakoglobin. J Biol Chem 1995;270:5549-55.

24. Marcus DM, Rustgi AK, Defoe DM, et al. Retinal pigment epithelium abnormalities in mice with adenomatous polyposis coli gene disruption. Arch Ophthalmol 1997;115:645-50.

25. Pack K, Smith-Raven J, Phillips RKS, Hodgson SV. Exceptions to the rule: individuals with FAP specific CHRPE and mutations in exon 6 of the APC gene. Clin Genet 1996;50:110-1.

26. Lynch HT, Smyrk T, McGinn T, et al. Attenuated familial adenomatous polyposis (AFAP): a phenotypically and genotypically distinctive variant of FAP. Cancer 1995;76:2427-33.

27. Soravia C, Berk T, Madlensky L, et al. Genotype-phenotype correlations in attenuated adenomatous polyposis coli. Am J Hum Genet 1998;62:1290-301.

28. Traboulsi EI, Krush AJ, Gardner EJ, et al. Prevalence and importance of pigmented ocular fundus lesions in Gardner's syndrome. N Engl J Med 1987;316:661-7.

29. Baba S, Tsuchiya M, Watanabe I, Machida H. Importance of retinal pigmentation as a subclinical marker in familial adenomatous polyposis. Dis Colon Rectum 1990;33:660-5.

30. Bunyan DJ, Shea-Shimonds J, Reck AC, et al. Genotype-phenotype correlations of new causative APC gene mutations in patients with familial adenomatous polyposis. J Med Genet 1995;32:728-31. 